\title{
CONSIDERATIONS AND REFLECTIONS ON GLOBALIZATION OF RESEARCH-SUPPORTED BEST PRACTICES AND QUALITY STANDARDS FOR ONLINE EDUCATION AND DIGITAL LEARNING
}

\author{
Yaping Gao \\ Ed.D \\ Quality Matters, USA \\ 1997 Annapolis Exchange Parkway, Suite 300, Annapolis, Maryland, USA 21401
}

\begin{abstract}
As much of the world is still facing and coping with the COVID-19 pandemic, what can we do, as a connected global educational community, to share research-supported best practices and quality standards for teaching and learning to support each other and help institutions and students achieve their educational goals? Can a US-based, research-supported approach to quality assurance and continuous improvement in online and digital learning, developed for and adopted by over 1200+ higher educational institutions, K-12 schools, and other educational organizations mainly in English-speaking communities for over 15 years, be adapted to educational systems and environments outside of USA? What strategies work best and what considerations need to be employed in initiating and sustaining collaborations and globalizations of best practices in culturally and pedagogically different educational communities?

The presenter from a leading US-based quality assurance organization will share their experience working with various institutions and organizations in non-English speaking regions and their strategies and considerations applied to initiate and develop collaborations and partnerships with the goal to contribute to the establishment of quality assurance processes for online, blended and digital learning for international communities.
\end{abstract}

\section{KEYWORDS}

International Collaboration, Globalization, Online Education, Digital Learning, Quality Assurance, Best Practices

\section{INTRODUCTION}

Can a US-based, research-supported approach to quality assurance and continuous improvement in online and digital learning, developed for and adopted by over 1200+ higher educational institutions, K-12 schools, and other educational organizations mainly in English-speaking communities for over 15 years, be adapted to educational systems and environments outside of USA? What strategies work best and what considerations need to be employed in initiating and sustaining collaborations and globalizations of best practices in culturally and pedagogically different educational communities?

\section{BODY OF PAPER}

\subsection{US-Based Research-Supported Quality Assurance Process:}

The primary components of the US-based quality assurance process includes: 1) five sets of research-supported standards (or rubrics) to guide the design, development and review of online courses and the online components of blended courses; 2) variety of customizable professional development offerings and tracks for administrators, faculty and instructional design support staff to apply the standards for course design, development, and review; 3) a peer-review process for online and blended course reviews resulting in 
constructive recommendations for continuous improvement, certification of quality and national recognition, and 4) implementation of the quality assurance process as pathway on a continuum to program excellence and student success, achievement of institutional goals, and facilitation of accreditation process.

\subsection{Reflections on Globalization of Best Practices and Quality Standards}

Several years' efforts in international outreach initiatives in the identified priority communities by the US-based leading quality assurance organization have resulted in many reflections and takeaways on the globalization of research-supported best practices and quality standards, including but not limited to:

1) Just because the research-supported quality standards and related services and processes work well with the majority of US-based institutions and organizations does not mean they will work as well for the international community.

2) Translation is the easiest part of it, but truly accurate translation needs not only high language proficiency, but also acute cultural awareness and complete immersion into the local culture, in addition to deep understanding of and experience in implementing the US-based standards and tools.

3) Adaption is more than translation. When it comes to adaption and localization of standards and services, one size does not fit all. Considerations or adaptations that are important or even essential in one culture or educational environment may not be considered as important or essential.

4) Educational systems and environments vary vastly from country to country, from region to region, and even from local bureau to local bureau depending on the hierarchical governance and regional and national accreditation structure.

5) Although online and blended learning has become mainstream in US and other English-speaking countries, for the rest of the world, it is just starting but with great potentials as the COVID-19 pandemic has pushed quality online and digital learning to the top of priority lists. There are much to be learned from each other and many opportunities to explore collaborations.

\section{CONCLUSION}

Despite the vast difference among the diverse international education communities in terms of language, culture, pedagogy, technology infrastructure, governance, and more, core elements of teaching and learning remain the same for all. Based on years of working with numerous international communities with very culturally and pedagogically different educational environments, feedback has been collected to formulate a set of international standards, which can be adopted and adapted by any educational institution or organization to help achieve their goals in student-centered learning in their locally prevailing delivery formats, be it online, blended, or technology-enhanced teaching and learning during, after and beyond the COVID-19 pandemic.

\section{REFERENCES}

Ding, Y., Gao, Y., \& Lu, F. (2017). The Development of QM-Fudan Higher Education Online Course Quality Standards, American Journal of Distance Education

Gao, Y., Legon, R. (2015) Internationalizing Quality Matters: The China Case, American Journal of Distance Education, $29: 3,210-219$

Quality Matters (2014), Quality Matters Higher Education Rubric Workbook, Fifth Edition Quality Matters website (www.qualitymatters.org ). Quality Matters research and related documents may be found at https://www.qualitymatters.org/research.

Quality Matters (2016), Quality Matters International Collaboration Principles and Guidelines

United States Distance Learning Association 2017 International Awards: https://www.usdla.org/awards/2017-awards-winners/ 